\title{
The efficiency of gas injection into low-permeability multilayer hydrocarbon reservoirs
}

\author{
Sudad H. AL-Obaidi', Miel Hofmann², Falah H. Khalaf ${ }^{3}$, Hiba H. Alwan ${ }^{4}$ \\ 1,2 Department of Petroleum Engineering, Mining University, Russia \\ ${ }^{3,4}$ Department of Petroleum Engineering, Knowledge University, Kurdistan, Iraq \\ Corresponding Author: Professor Sudad H. AL-Obaidi, drsudad@gmail.com
}

\begin{abstract}
The efficiency of gas injection for developing terrigenous deposits within a multilayer producing object is investigated in this article. According to the results of measurements of the 3D hydrodynamic compositional model, an assessment of the oil recovery factor was made. In the studied conditions, re-injection of the associated gas was found to be the most technologically efficient working agent.

The factors contributing to the inefficacy of traditional methods of stimulating oil production such as multistage hydraulic fracturing when used to develop low-permeability reservoirs have been analysed. The factors contributing to the inefficiency of traditional oil-production stimulation methods, such as multistage hydraulic fracturing, have been analysed when they are applied to low-permeability reservoirs.

The use of a gas of various compositions is found to be more effective as a working agent for reservoirs with permeability less than $0.005 \mu \mathrm{m}^{2}$. Ultimately, the selection of an agent for injection into the reservoir should be driven by the criteria that allow assessing the applicability of the method under specific geological and physical conditions. In multilayer production objects, gas injection efficiency is influenced by a number of factors, in addition to displacement, including the ratio of gas volumes, the degree to which pressure is maintained in each reservoir, as well as how the well is operated. With the increase in production rate from 60 to $90 \mathrm{~m}^{3}$ / day during the re-injection of produced hydrocarbon gas, this study found that the oil recovery factor increased from 0.190 to 0.229 . The further increase in flow rate to $150 \mathrm{~m}^{3} /$ day, however, led to a faster gas breakthrough, a decrease in the amount of oil produced, and a decrease in the oil recovery factor to 0.19

Based on the results of the research, methods for stimulating the formation of low-permeability reservoirs were ranked based on their efficacy.
\end{abstract}

Keywords. Gas injection, Low permeability reservoir, Multilayer formation, Reservoir pressure maintenance, Formation stimulation.

\section{Introduction}

It is often ineffective to develop oil fields with low-permeability reservoirs by using the traditional reservoir pressure maintenance (RPM) method such as multistage hydraulic fracturing (MSHF) [1-5]. The practice of developing low permeability reservoirs shows how the system differs significantly from the classical water-flooding method, which has shown to be an effective method for increasing the recovery of oil in terrigenous reservoirs with high flow properties. 
Moreover, the possibility of using various compositions of gases as working agents can be an advantage when considering hard-to-recovery reserves (HTRR) as promising targets for development with the achievement of higher oil recovery factors (RF) [6-10]. It is imperative to measure the economic and technical efficiency of this approach in light of the policy of oil and gas companies to encourage profitable development of low-permeability fields [11-13].

\section{Inefficiency of Using Traditional Pressure Maintenance Methods in the Development of Low Permeability Reservoirs}

Traditionally, the development of hydrocarbon fields with hard-to-recover reserves involves either hydraulic fracturing as a method of enhanced oil recovery (EOR) with further reliance on the field's own energy or water injection [14-17]. In spite of this, using water as a working agent to maintain reservoir pressure yields no tangible results. Thus, for reservoirs with permeability less than $0.025 \mu \mathrm{m}^{2}$ and a $90 \%$ water cut, the maximum actual withdrawal of initial recoverable reserves (IRR) is $41.6 \%$ of its calculated value. Reservoirs with permeability less than $0.010 \mu \mathrm{m}^{2}$ have actual oil recovery factors in the range of 0.014 to 0.235 , with an average value of 0.138 . In general, with a water cut of about $80 \%$, the withdrawal of initial recoverable reserve is not more than $35-40 \%$ of its calculated value [18-21]. With such ratios of water cut and oil recovery, it can be argued that with the existing development system based on water injection, the calculated values of oil recovery factors are overestimated and will not be achieved [22-24]. Figure 1 shows the ratios of the initial recoverable reserves and the water cut in production during the implementation of the water flooding system.

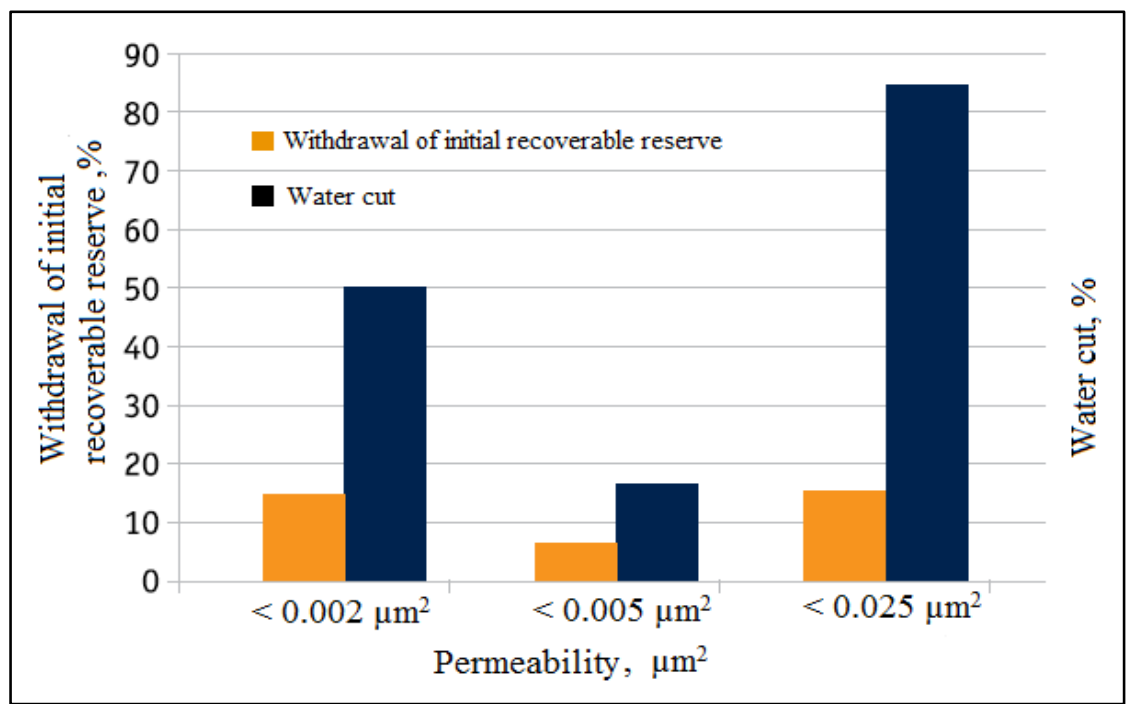

Figure1. Developing low-permeability reservoirs: Ratio of withdrawals of initial recoverable reserves and water cut

In the case of reservoirs with low flow characteristics and permeability less than $0.010 \mu \mathrm{m}^{2}$, there can be a discrepancy of $70 \%$ or more between the design and actual values of oil recovery factor. In this context, reservoirs with such flow characteristics cannot be considered as promising objects for the implementation of a water-flooding system [25-28].

\section{Potential Of Using Gas In The Development Of Low Permeable Reservoirs}

One of the most promising methods for increasing displacement efficiency and RPM in a lowpermeability reservoir is to use gaseous agents [29 - 33].

Several oil companies and research organizations have studied the phenomenon of oil displacement by gaseous compositions in laboratory conditions both on a real core and on combined bulk models. 
Moreover, they perform numerous experiments using 3D hydrodynamic modelling (HDM), the results of which are widely used to evaluate and justify options for the development of oil and oil and gas condensate deposits with the injection of gaseous compositions [34-37].

With respect to the evaluation of gas based EOR efficiency, ranking and searching for the best source of gas in terms of efficiency can be done in two directions: with restrictions on the source of production and, accordingly, on the composition of the gas [38-40].

\subsection{Field study}

The last approach (composition of the gas) was used to assess the prospects for developing terrigenous deposits in the studied formation. The layers of the studied formation are characterized by low values of oil-saturated thickness - up to $5.0 \mathrm{~m}$, the reservoir permeability does not exceed 0.005 $\mu \mathrm{m}^{2}$ and the viscosity of the reservoir oil is less than $1 \mathrm{mPa}$.s. The field study identified a multi-layer production facility with a $100 \mathrm{~m}$ difference in depth between upper and lower layers, which meets the requirements for layer combining.

Before starting the calculations, a thorough assessment of the geological and physical conditions was performed to determine whether each of the gases, which could theoretically be used to stimulate oil inflow, met the applicable criteria. The results of ranking from best to worst are shown in Fig.2.

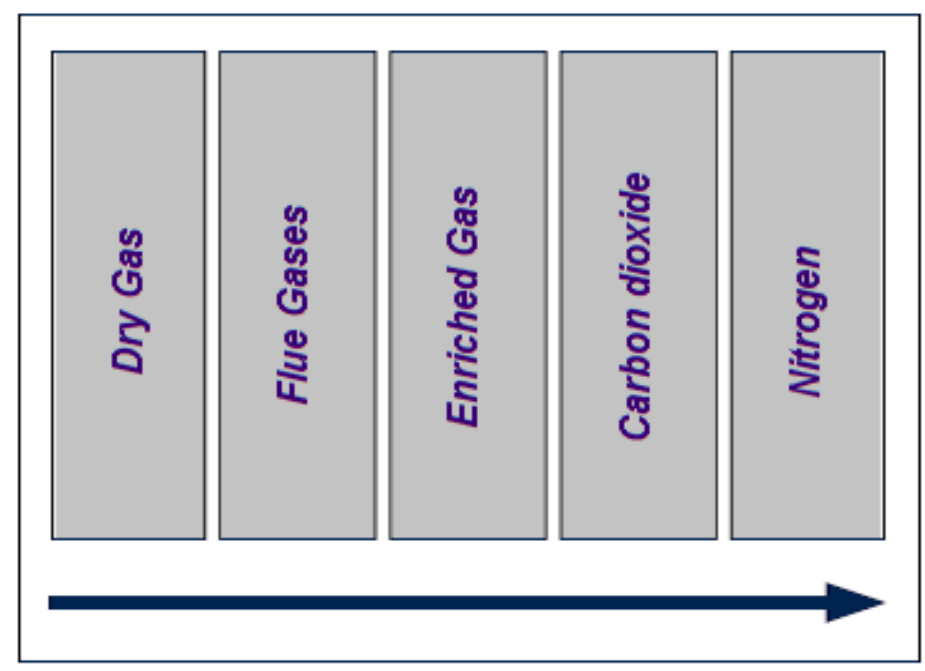

Figure 2. Gas stimulation methods ranked by criteria of applicability on a low-permeability reservoir (best to worst)

The calculations were performed using a commercial hydrodynamic simulator in the compositional modeling option [41, 42]. The models were different in their injected agent composition and well operation modes. As a base case, the field was developed in the depletion mode, which allowed the field to reach the oil recovery factor of 0.063 .

There is a characteristic feature of wells operating in a low-permeability reservoir in that they experience a significant drop, more than twice, in production rate already within the first year (Fig. 3). 


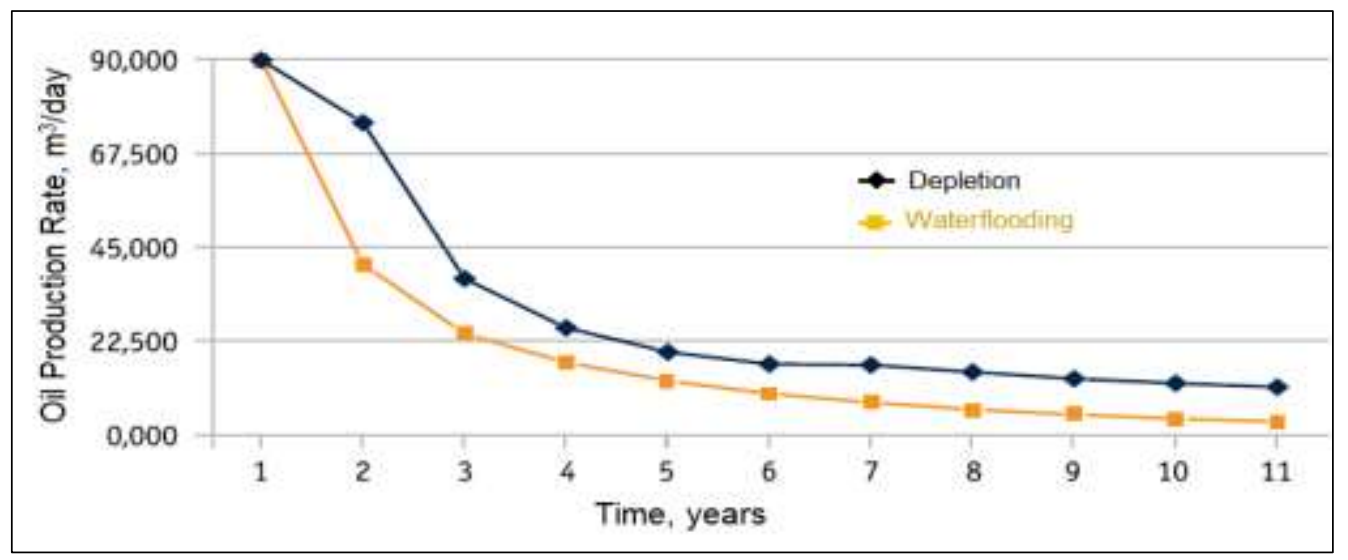

Figure 3. The drop in oil production rates of wells both during the natural mode of development and during water flooding

\section{Results and discussions}

Based on calculations, there is no way to effectively maintain reservoir pressure with water injection, which takes into account the preparation quality and low reservoir properties (permeability and porosity). In waterflooding, well production rates differed slightly from the dynamics in the natural regime, and the estimated oil recovery factor was 0.109 . Due to the implementation of water injection in reservoirs with permeability less than $0.005 \mu \mathrm{m}^{2}$, oil recovery factor increased by 0.015 unit fraction.

The efficiency of gas injection into a low-permeability reservoir has been calculated based on a compositional model with specified thermobaric conditions [43-45]. For each option, the volume of injected gas was assumed to be the same, except for the option with the re-injection of produced gas, which was based on the amount of oil production. The injection efficiency of each type of gas was evaluated for an equal period, determined by the time it took to reach monotonically decaying dynamics (Fig. 4).

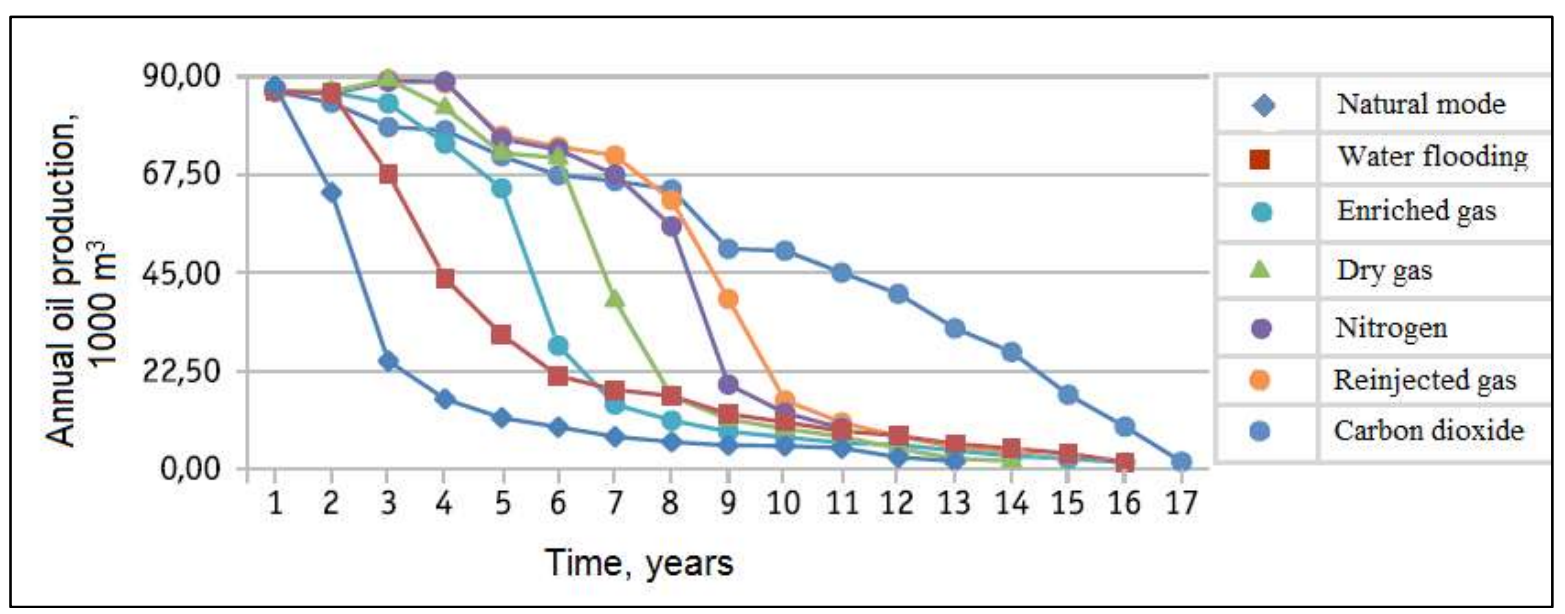

Figure 4. Estimates of annual oil production based on treatment options

In multilayer production facilities, the injection volume is redistributed according to factors such as the physical properties of gas, temperature and pressure conditions, and reservoir properties. In each reservoir, this redistribution will determine the type of displacement and the degree of reservoir 
pressure maintenance (RPM) [46-48]. Calculations reveal that increasing propane-butane content in the produced gas by $35 \%$ resulted in an increase of oil recovery factor by about $22 \%$ when the composition of the gas was changed (from dry to enriched).

As a result of injecting nitrogen, carbon dioxide (CO2), methane, and enriched gas in all formation layers for 2-4 years, reservoir pressure increased by $5.7 \mathrm{MPa}$ in the upper layer and by $2.0 \mathrm{MPa}$ in the lower layer (Fig. 5).

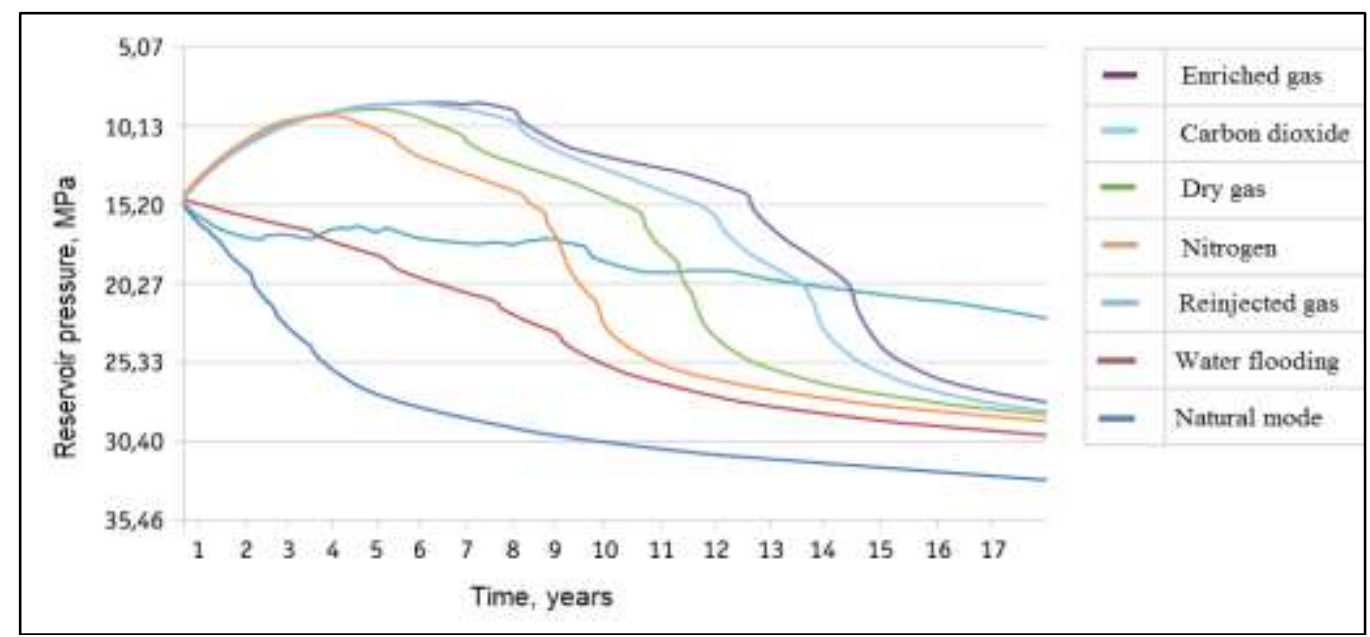

Figure 5. Reservoir pressure dependence on the stimulation option (upper reservoir)

During injection of any gas composition under the given thermobaric conditions (reservoir pressure $\mathrm{P}_{\mathrm{r}}=24.0 \mathrm{MPa}$, reservoir temperature $\mathrm{T}_{\mathrm{r}}=100^{\circ} \mathrm{C}$ ) and oil composition, an immiscible displacement pattern is achieved. Miscible displacement is only possible in the upper formation in a limited bottomhole zone when injecting $\mathrm{CO}_{2}$, enriched, and re-injected gas with a propane-butane mass fraction of $24.8 \%$.

It is observed that reservoir pressure is decreased during re-injection of produced gas and water, as well as during natural depletion. The decrease in reservoir pressure during waterflooding is explained by a low flow rate for reservoirs with a low permeability. During gas re-injection, decreases in reservoir pressure $\left(\mathrm{P}_{\mathrm{r}}\right)$ are particularly noticeable at the beginning due to limited production volumes. By increasing the development period, the volumes of produced gas will increase, therefore, the volume of injected gas will increase as well.

In the underlying layer, reservoir pressure is maintained at a lower level than in the overlying layer. The calculated oil recovery factor (RF) values are given in Table 1.

Table1. Estimated values of the oil recovery factor

\begin{tabular}{|l|c|}
\hline \multicolumn{1}{|c|}{ Method of impact } & Oil recover factor, \% \\
\hline Methane injection & 14.6 \\
\hline Gas re-injection & 22.9 \\
\hline Enriched gas injection & 17.8 \\
\hline Carbon dioxide injection & 16.9 \\
\hline Nitrogen injection & 12.0 \\
\hline Natural mode & 6.3 \\
\hline Waterflooding & 11.4 \\
\hline
\end{tabular}


Further, it is important to note that the obtained oil recovery factor values do not only depend on the displacement factors, but also on the volume of penetrated gas in the reservoirs, as well as the possibility and duration of reservoir pressure maintenance, which had a large impact on the change in sweep efficiency $[49,50]$. Under the studied conditions, re-injection of associated gas was found to be the most technologically efficient working agent.

It is apparent that when implementing gas stimulation methods, not only the composition of the injected gas and injection parameters ought to be determined, but also technological modes of operation of the producing wells for each composition of gas [51 - 53]. Thus, during the re-injection of the produced hydrocarbon gas with an increase in the production rate from 60 to $90 \mathrm{~m}^{3} /$ day, the oil recovery factor increased from 0.190 to 0.229 . Further increase in flow rate to $150 \mathrm{~m}^{3} /$ day, however, led to a faster gas breakthrough, a decrease in the share of oil produced, and a decrease in the oil recovery factor to 0.192 .

\section{Conclusions}

When a reservoir has low flow and capacity reservoir properties, with a permeability of less than $0.005 \mu \mathrm{m}^{2}$, waterflooding cannot be considered as an effective stimulation method. Due to the implementation of water injection in reservoirs with permeability less than $0.005 \mu \mathrm{m}^{2}$, oil recovery factor increased only by 0.015 unit fraction. Meanwhile, gases of various compositions were found to be more effective as a working agent in reservoirs with permeability less than $0.005 \mu \mathrm{m}^{2}$. In this case, When changing the composition of the gas (from dry to enriched), increasing propane-butane content by $35 \%$ resulted in an increase of oil recovery factor by about $22 \%$.

Therefore and as the primary development method, gas injection is necessary. Which wells are operated and how they are operated must be determined according to the complex geological and geophysical characteristics of the reservoir. In this case, when the hydrocarbon gas was re-injected with an increase in production rates from $60 \mathrm{~m}^{3} /$ day to $90 \mathrm{~m}^{3} /$ day, the oil recovery factor increased from 0.190 to 0.229 . Moreover, injection of different types of gas compositions in all formation layers resulted in reservoir pressure increasing by 2.0 to $5.7 \mathrm{MPa}$.

\section{References}

[1] Glavnov N.G., Vershinina M.V., Penigin A.V.\& et al., 2019. Miscible gas injection to increase oil recovery . Professionally about oil 2 (12) 25-29.

[2] Al-Obaidi, S. \& Khalaf, F., 2019. Development Of Traditional Water Flooding to Increase Oil Recovery. International Journal of Scientific \& Technology Research 8(01) $177-181$.

[3] Al-Obaidi, S., Smirnov, V. \& Alwan, H., 2021. Experimental Study about Water Saturation Influence on Changes in Reservoirs Petrophysical Properties, Walailak J Sci \& Tech. 18(13). doi:10.48048/wjst.2021.20594.

[4] Smirnov, V. \& Al-Obaidi, S., 2008. Innovative Methods of Enhanced Oil Recovery. Oil Gas Res 1: e101. doi: 10.4172/2472-0518.1000e10.

[5] Krasnoborov S.V. \& Byakov A.V., 2014. Evaluation of the choice of an injection agent in the development of the Achimov deposits of Western Siberia with hard-to-recover oil reserves and abnormally high reservoir pressure. Drilling and oil (9) 44-46.

[6] Al-Obaidi S., 2007. Analysis of Hydrodynamic Methods for Enhancing Oil Recovery. Journal of Petroleum Engineering and Technology 6(3), 20 - 26.

[7] Mishchenko I.T. \& Nazarova L.N., 2015. Justification of the boundary values of the final oil coefficient for terrigenous formations developed with the use of waterflooding.Proceedings of the Russian State University of Oil and Gas named after I.M. Gubkin 3 (280) 49-55.

[8] Al-Obaidi, S., 2004. Modified Use of Microbial Technology as an Effective Enhanced Oil Recovery. OSF Preprints, doi:10.31219/osf.io/xgthz. 
[9] Sharafutdinov R.F., Grachev S.I., Nesterenko A.N. \& et al., 2017. Results of laboratory and experimental studies on physical modeling of oil displacement by various agents. Exposition Oil Gas 3 (56) 28-33.

[10] AL-Obaidi, S., Smirnov, V. \& Khalaf, F., 2020. New Technologies to Improve the Performance of High Water Cut Wells Equipped With ESP, Technium 3(1)104 - 113.

[11] Al-Obaidi, S., Khalaf, F. \& Alwan, H., 2021. Performance Analysis of Hydrocarbon Wells Based on the Skin Zone. Technium 3(4), 50 - 56.

[12] Patkin, A. \& Al-Obaidi, S., 2001. Influence of Temperature and Pressure of Incoming OilContaining Liquid from Field Wells on the Gas Separation Process. Journal of Petroleum Engineering and Emerging Technology 3(4), 20 - 24.

[13] Chusovitin A.A., Gnilitskiy R.A., Smirnov D.S. \& et al., 2016. Evolution of design solutions for the development of deposits of the Tyumen suite on the example of the deposits of the Krasnoleninsky arch. Oil industry (6) $54-58$.

[14] Al-Obaidi, S., 2016. High Oil Recovery Using Traditional Water-flooding under Compliance of the Planned Development Mode. Journal of Petroleum Engineering \& Technology 6(2), 48 - 53.

[15] Al-Obaidi, S. \& Khalaf, F., 2017. Acoustic Logging Methods in Fractured and Porous Formations. J. Geol. Geophys. 6, 1000293.

[16] Garifullin R.I., Verscheure M., Karpov S.N. \& et al., 2015. New opportunities in the field of multistage hydraulic fracturing modeling in horizontal wells. Subsoil use XXI century 4 (54) 48 53.

[17] Al-Obaidi, S., 2016. Improve the Efficiency of the Study of Complex Reservoirs and Hydrocarbon Deposits-East Baghdad Field”. International journal of scientific \& technology research, 5(8), $129-131$.

[18] Al-Obaidi, S. \& Hofmann, M ., 2012. Prediction of Current Production Rates, Cumulative Production and Recoverable Reserves of Hydrocarbon Fields. OSF Preprints. doi:10.31219/osf.io/67qmt.

[19] Minich A.A., Timirgalin A.A., Butorina M.G. \& et al., 2018. Technologies as a key to the development of reserves of the Achimov strata. Oil industry (12) 30-33.

[20] Al-Obaidi, S., 1999. Submersible Screw Pumps in Oil Industry. Journal of Petroleum Engineering and Emerging Technology 3(7), 10 - 13.

[21] Al-Obaidi SH \& Khalaf FH, 2017. The Effect Of Anisotropy In Formation Permeability On The Efficiency Of Cyclic Water Flooding. International Journal of Scientific \& Technology Research 6 (11) 223-226.

[22] Petrakov A.M., Egorov Yu.A. \& Nenartovich T.L., 2018. System-methodical aspects of physical modeling of gas and water-gas impact on the oil reservoir. Oil industry (9) 68-74.

[23] Al-Obaidi, S., Guliaeva, N. \& Khalaf, F., 2020. Thermal Cycle Optimization when Processing the Bottom-Hole Zone of Wells. International Research Journal of Modernization in Engineering Technology and Science 2(11), $266-270$.

[24] Al-Obaidi, S., 2015. The Use of Polymeric Reactants for EOR and Waterproofing. Journal of Petroleum Engineering and Emerging Technology 1(1), 1 - 6.

[25] H. Liu, P. Ye, W. Li, L. Song \& Y. Zhong, 2010. Application of nitrogen foam for profile modification in a heterogeneous multi-layer sandstone oilfield. Geothermics 32 (4) 173-188.

[26] Al-Obaidi Sudad H., 1990. Comparison of Different Logging Techniques for Porosity Determination to Evaluate Water Saturation. engrXiv, 10.31224/osf.io/fvj9u.

[27] Hofmann M., AL-Obaidi S.H. \& Kamensky I.P., 2021. Calculation Method for Determining the Gas Flow Rate Needed for Liquid Removal from the Bottom of the Wellbore. J Geol Geophys 10 (5) $1-5$.

[28] Al-Obaidi, S., Hofmann, M. \& Kamensky, I., 2010. Changes in the Physical Properties of Hydrocarbon Reservoir as a Result of an Increase in the Effective Pressure During the Development of the Field. JoPET 1(5),16-21. 
[29] Al-Obaidi, S. \& Guliaeva, N., 2002. Determination of Flow and Volumetric Properties of Core Samples Using Laboratory NMR Relaxometry. JoPET 1(2), 20 - 23.

[30] Wang, Q, Yang, S, Lorinczi, P \& et al., 2020. Experimental Investigation of Oil Recovery Performance and Permeability Damage in Multilayer Reservoirs after $\mathrm{CO} 2$ and WaterAlternating-CO2 (CO2-WAG) Flooding at Miscible Pressures. Energy \& Fuels 34 (1) 624-636.

[31] Al-Obaidi SH \& Khalaf FH, 2020. Prospects for improving the efficiency of water insulation works in gas wells International Research. Journal of Modernization in Engineering Technology and Science 2 (9) 1382-1391.

[32] Al-Obaidi, S., 1998. Areas of Effective Application of Submersible Centrifugal Pump Installations with and Without a Gas Separator. engrXiv,10.31224/osf.io/2c84h.

[33] Jun Xie, Xiao Hu, Huizhen Liang \& et al., 2020. Experimental investigation of permeability heterogeneity impact on the miscible alternative injection of formation Brine-Carbon dioxide. Energy Reports (6) 2897-2902.

[34] Al-Obaidi, S., Kamensky, P., \& Smirnov, V., 2020. Investigation of Thermal Properties of Reservoir Rocks at Different Saturation. International Research Journal of Modernization in Engineering Technology and Science 2 (1) 12-16. doi:10.31224/osf.io/qtahw.

[35] Hofmann, M, Al-Obaidi, S. \& Patkin, A., 2013. Problems of Transporting"Heavy" Gas Condensates at Negative Ambient Temperatures and Ways to Solve These Problems, JoPET 3(3), 31 - 35. doi:10.31224/osf. io/fw57b.

[36] AL-Obaidi Sudad H., 2009. Experimental Study of The Influence of Fluid Flow Rate on The Risk of Rock Destruction. Journal of Petroleum Engineering and Emerging Technology 9 (4) 8489.

[37] Al-Obaidi SH \& Khalaf FH, 2018. The Effects Of Hydro Confining Pressure On The Flow Properties Of Sandstone And Carbonate Rocks. International journal of scientific \& technology research 7 (4) 283-286.

[38] Pengcheng Liu \& Xiaokun Zhang, 2015. Enhanced oil recovery by CO2-CH4 flooding in low permeability and rhythmic hydrocarbon reservoir. International Journal of Hydrogen Energy 40 (37) $12849-12853$.

[39] Al-Obaidi, S., Chang, W. \& Khalaf, F., 2021. Determination of the Upper Limit up to Which the Linear Flow Law (Darcy's Law) Can Be Applied. Journal of Xidian University 15(6), 277 286, doi: 10.37896/jxu15.6/029.

[40] Chang WJ , AL-Obaidi SH \& Patkin AA., 2021. Assessment Of The Condition Of The NearWellbore Zone Of Repaired Wells By The Skin Factor. International Research Journal of Modernization in Engineering Technology and Science 3 (4) 1371-1377.

[41] Gimazova GK \& et al., 2014. Review of methods of enhanced oil recovery by flow diversion and leveling of the injectivity profile. Bulletin of Kazan Technological University (4) 257-262.

[42] Al-Obaidi, S. \& Galkin, A., 2005. Dependences of Reservoir Oil Properties on Surface Oil. Jo Pet. Eng. Emerg. 5, $74-77$.

[43] KamenskyIP , AL-Obaidi SH \& Khalaf FH, 2020. Scale effect in laboratory determination of the properties of complex carbonate reservoirs. International Research Journal of Modernization in Engineering Technology and Science 2 (11) 1-6.

[44] Al-Obaidi, S., Smirnov, V. \& Kamensky, I., 2019. Investigation of Rheological Properties of Heavy Oil Deposits. International Journal Of Scientific \& Technology Research 8(9), 2394 2397.

[45] Churikova L.A. \& Amirlan Baurzhanuly Bayangali, 2019. Efficiency of oil and gas condensate field development using a reservoir pressure maintenance system. Young scientist 47 (285) 138142.

[46] Sudad H AL-Obaidi, 2020. A way to increase the efficiency of water isolating works using water repellent. International Research Journal of Modernization in Engineering Technology and Science 2 (10) 393-399. 
[47] Al-Obaidi, S., Galkin, A. \& Patkin, A., 2006. Prospects of High Viscosity Oil Flow Rate in Horizontal Wells. JoPET 5(4), $56-62$.

[48] Chang W.J., AL-Obaidi S.H. \& Patkin A.A., 2021. The Use Of Oil-Soluble Polymers To Enhance Oil Recovery In Hard To Recover Hydrocarbons Reserves. International Research Journal of Modernization in Engineering Technology and Science 3(1) 982-987.

[49] AL-Obaidi SH, Patkin AA \& Guliaeva NI, 2003. Advance Use For The NMR Relaxometry To Investigate Reservoir Rocks. JoPET 2(3) 45-48.

[50] Al-Obaidi SH, 2017. Calculation Improvement of the Clay Content in the Hydrocarbon Formation Rocks. Oil Gas Res 3:130. doi: 10.4172/2472-0518.1000130.

[51] W. Su, J. Hou, T. Zhao, Y. Xi \& C. Cui, 2017. Experimental investigation on continuous $\mathrm{N}_{2}$ injection to improve light oil recovery in multi-wells fractured-cavity unit. Petroleum 3 (3) $367-376$.

[52] AL-Obaidi SH, Guliaeva NI \& Smirnov VI, 2020. Influence of structure forming components on the viscosity of oils. International Journal Of Scientific \& Technology Research 9 (11) 347351.

[53] Xie J, Hu X, Liang H, Li Z, Wang R \& et al., 2020. Experimental investigation of permeability heterogeneity impact on the miscible alternative injection of formation Brine-Carbon dioxide. Energy Rep 6:2897-2902.

[54] Al-Obaidi, S. \& Guliaeva, N., 2017. Thermal Adsorption Processing of Hydrocarbon Residues. International Journal of Scientific \& Technology Research 6(4), 137 - 140. 